American Societies which took place at San José, Costa Rica. One of the principal activities is being pursued most effectively by the women's committees and held an important place in the discussions on first-aid.

Recommendations were then passed of which these were the most significant : Societies should be exempt from customs duty on products which they have to import-Courses on the Red Cross should be introduced into school programmes-In the case of natural disasters or conflict, Red Cross personnel should be able to go freely throughout Central America from one country to another-Junior Red Cross work should be intensified-National Societies must be able to count continuously on trained personnel and be provided with mobile equipment to ensure rapid communication.

\title{
Dominican Republic
}

The Dominican Red Cross is now producing a monthly publication, Boletin Informativo de la Cruz Roja Dominicana, whose first number in March 1966 contains interesting details on the National Society's present work and plans. Due credit should be given to this useful medium of information whose object is defined as "to enable our members and provincial and municipal committees to become acquainted with the tasks which have been accomplished and which are motivated by our fundamental principles. We call upon all volunteers who may wish to co-operate with us and we offer them the opportunity of discussing their projects, humanitarian work and ideals."

In an editorial followed by a study entitled "What the Red Cross is and what its principles are", mention is made of Solferino, of Dunant's book and undertakings, of the setting up of the Committee of Five and also of the first international meeting in Geneva in 1864 of delegates from 16 different countries. Another article deals with a subject which we know was discussed at length at the International Conference last year in Vienna, that of civil defence and the necessary intervention on the part of the State. 
Account is also given of new tasks and of those which are being extended further. For example, the National Society is concerning itself with reorganising the Junior Red Cross whose new head has already made contact with all the schools in the capital and with various departments which might themselves be in a position to help in drawing up a first project, that of arranging for travel into the interior. Furthermore, 150 young, both boys and girls, have attended courses in first-aid, life-saving and nautical training for which they have obtained diplomas.

The Dominican Republic has increasing need of people with a knowledge of treating the sick of hygiene, of public health and homecare. The National Society is fully aware of this fact and it has consequently increased the number of courses in that sphere and a registered nurse is now in charge of the home-care section. She will herself be attending a course at Managua, Nicaragua, so as to be able to give instruction in the subject to female voluntary workers.

\section{India}

An article in the May issue of the International Reviere was devoted to the XXth award of the Florence Nightingale Medal. It mentioned that this medal was awarded to one of India's nurses in 1965, namely Miss Florence St.Claire Watkins. The presentation took place recently so that we were not previously able to give an account of that ceremony. We did describe the medalist's merits and we therefore need not repeat her citation.

On April 26, 1966, the President of India, Dr. S. Radhakarishnan, presented the medal to Miss Watkins during the National Society's General Meeting which took place at the Presidential Palace in New Delhi ${ }^{1}$. The noble personality of he who presented the medal and the signal services rendered by the recipient gave added dignity to the ceremony.

${ }^{1}$ Plate: The President of India presenting the Florence Nightingale Medal to Miss Watkins. 